\title{
Germ cell-less like-2 protein is a new component of outer dense fibers in rat sperm flagella
}

\author{
Emi Murayama, Michiko Katoh, Akina Kanebayashi, Takane Kaneko, Yosaburo Shibata ${ }^{1}$, \\ Tetsuichiro Inai ${ }^{1}$ and Hiroshi lida \\ Laboratory of Zoology, Graduate School of Agriculture, Kyushu University, Higashiku Hakozaki 6-10-1, Fukuoka \\ 812-8581, Japan and ${ }^{1}$ Department of Developmental Anatomy, Graduate School of Medical Science, Kyushu \\ University, 3-1-1 Maidashi, Fukuoka 812-8582, Japan \\ Correspondence should be addressed to H lida; Email: iidahiro@agr.kyushu-u.ac.jp
}

E Murayama and M Katoh contributed equally to this work

\begin{abstract}
We have analyzed the expression profiles of ten genes in terms of testis development and organ specificity in rat, which were selected from 215 round spermatid-specific transcripts listed in a database. Out of the ten genes, we directed our attention to one gene, a germ cell-less like-2 gene ( $\mathrm{gcl}-2)$, a homolog of Drosophila gcl gene $(\mathrm{gcl})$, which is a component of the germ plasma and required for primordial germ cell formation. Rat genome contains duplicate rat gcl-2 ( $\mathrm{rgcl}-2)$ genes, $\mathrm{rgcl}-2 \mathrm{~A}$ and $\mathrm{rgcl}-2 \mathrm{~B}$, both of which are located at Xq13. RT-PCR analysis showed that the expression of the two genes was up-regulated during testis development and that they were predominantly expressed in the testis. Both $\mathrm{rgcl}-2 \mathrm{~A}$ and $\mathrm{rgcl}-2 \mathrm{~B}$ encode a protein of 498 amino acid residues, showing $90.56 \%$ identity at the amino acid level. Confocal laser scanning microscopy revealed that rgcl-2 protein was synthesized in the cytoplasm of elongating spermatids and at least a part of it was integrated into the middle piece of spermatozoa during spermiogenesis. Immunogold electron microscopy uncovered that rgcl-2 was localized at the abaxial (convex) surface of outer dense fibers (ODF) of rat sperm flagella. Therefore, we concluded that rgcl-2 is a new component of ODF in sperm flagella.

Reproduction (2007) 134 749-756
\end{abstract}

\section{Introduction}

Spermatogenesis is a highly complicated process that is initiated by the mitosis of spermatogonia followed by two meiotic divisions of spermatocytes. Haploid spermatids produced by meiosis enter the final spermatogenic stage, called spermiogenesis, in which spermatids undergo drastic morphological changes, such as nuclear condensation, acrosome formation, mitochondrial sheath construction, flagellum formation, and extrusion of residual cytoplasm (Leblond \& Clermont 1952, Clermont 1972). This tightly regulated process accompanying meiotic progression and the drastic changes in cell morphology suggest the presence of a highly organized network of genes expressed during spermatogenesis. The regulation of gene expression during spermatogenesis is controlled in three ways: intrinsic, interactive, and extrinsic (Eddy 2002). The intrinsic program of gene expression determines which genes and when they are expressed. The interactive process between germ cells and somatic Sertoli cells is required for proliferation and differentiation of spermatogenic cells. The extrinsic factors, such as steroid hormones, regulate the germ-Sertoli interactive process. Out of these three levels of gene regulation, the intrinsic genetic program is highly related to germ cell- and stage-specific gene expression in the testis.

Recent high-throughput genomics projects have focused on the identification of organism- and tissuespecific transcriptomes by which fundamental insights into biological processes, such as spermatogenesis, are expected to be clarified. Databases for expressed sequence tags (ESTs) provide important information for the discovery of novel genes with tissue-specific expression profiles (Hong et al. 2005). Recently, microarray has been utilized to understand the changes of gene expression during spermatogenesis. A genomewide transcriptional analysis of developing mouse testis was performed by Shima et al. (2004) using Affymetrix GeneChip system, and stage-specific transcripts were listed as the supplemental data at the Griswold Lab homepage (http://www.wsu.edu/ griswold/microarray). Out of the 215 round spermatid-specific transcripts listed in the database, we selected 10 genes and analyzed their expression profiles in terms of testis development and organ specificity. Among the ten genes, we focused our 
attention on one gene, a rat homolog of Drosophila germ-cell less $(\mathrm{gcl})$ gene, which encodes a protein of $57.6 \mathrm{kDa}$ that is predominantly expressed in elongating spermatids and integrated into the middle piece of sperm flagella as a component of outer dense fibers (ODF).

\section{Results \\ RT-PCR}

A genome-wide transcriptional analysis of the developing murine testis and spermatogenesis has been done using the Affymetrix GeneChip system (Shima et al. 2004), and the data are in a searchable form via the Mammalian Reproductive Genetics database (http://mrg.genetics.washington.edu). Complete lists of transcripts of stage-specific transcripts will be available as supplemental data through the Griswold Lab homepage (http://www.wsu.edu/ griswold/microarray). From the list of the 215 ESTs specific for round spermatids, the characterized known genes were first excluded. From the subtracted list, we chose 50 mouse genes that were also deposited in the RIKEN full-length-rich cDNA library at the $\mathrm{NCBI}$ database. These 50 mouse genes were narrowed down to 10 genes based on the following criteria: (1) a putative full-length ortholog gene was also found in rat cDNA database, which winnowed the candidates down from 50 to 31 and (2) a gene encodes a protein containing at least one domain or motifs by which 31 genes were narrowed down to 10 genes. We performed RT-PCR to examine the developmental expression of the ten genes in testis of 1- to 8-week-old rats as well as organ-specific expression of the genes by which we found that one gene was predominantly expressed in the testis and its expression level was up-regulated during testis development. In this study, we undertook to characterize the gene.

\section{Sequence and genomic organization of gcl-2 gene}

A search in NCBI and DNA Data Bank of Japan (DDBJ) databases employing the FASTA and BLAST programs revealed that the sequence of the gene described above was identical to that of mouse germ-cell less like-2 ( $m g \mathrm{Cl}-2$, accession no. NM_027955). Rat ortholog gene (rgCl-2 gene, accession no. XM_228797) was found in the $\mathrm{NCBI}$ database. Based on the sequence data of the rat $\mathrm{rgCl}-$ 2 gene, we made primers for PCR, and performed RT-PCR to obtain full-length $\mathrm{rgCl}$-2, which resulted in amplification of 1497 base-length DNA. The open reading frame (ORF) of $\mathrm{rgCl}_{-} 2$ encodes a protein of 498 amino acid residues (Fig. 1) with the predicted molecular mass 57578 Da and pl 8.45. SMART (http://smart.embl-heidelberg.de/) and NCBI Conserved Domain Search (http://www.ncbi.nlm. nih.gov/Structure/cdd/wrpsb.cgi) suggested the presence of a BTB (broad-complex, tramtrack and bric-a-brac) domain at 80-191 amino acid residues in rgcl-2. The BTB domain, which is also known as the POZ (pox virus and zinc finger) domain, mediates homomeric dimerization and in some instances heteromeric dimerization. A search in the NCBI and DDBJ databases employing the FASTA and BLAST programs revealed that the rat rgcl-2 (XM_228797) shared $79.72 \%$ identity with mouse mgcl-2 (accession no. NM_027955) at the amino acid level and $84.84 \%$ at the nucleic acid level.

To determine the genomic organization of $\mathrm{rgCl}-2, \mathrm{rgCl}-2$ cDNA was BLAST-searched against the rat genomic databases at NCBI. The results uncovered that $\mathrm{rgcl}-2$ gene is mapped as duplicate intron-less genes at $\mathrm{Xq} 13$ of $\mathrm{X}$ chromosome (Fig. 2A). These two $\mathrm{rgCl}$-2 were designated as rgCl-2A (accession no. XM_228797) and rgCl-2B (accession no. BC083583) in this study, both of which encode 498 amino acid residue-length proteins. RgCl-2A showed $94.39 \%$ identity with $\mathrm{rgCl}-2 \mathrm{~B}$ at the nucleic acid level and $90.56 \%$ identity at the amino acid level (Fig. 1). The molecular masses of $\mathrm{rgcl}-2 \mathrm{~A}$ and $\mathrm{rgcl}-2 \mathrm{~B}$ are 57.6 and $57.7 \mathrm{kDa}$ respectively and the pl values of these proteins are 8.45 and 8.15 respectively. These paralog genes seem to be produced by gene duplication during the course of evolution.

To examine the individual expression profiles of these two genes, we performed RT-PCR using $5^{\prime}$ primer common to both genes and $3^{\prime}$ primer specific to each gene. The lengths of the PCR products of $\mathrm{rgCl}-2 \mathrm{~A}$ and rgCl-2B were 990 and 823 bp respectively. As shown in Fig. 2B, they exhibited similar expression pattern in the testis of 1 - to 8 -week-old rats. They were detected at 4 weeks postnatal development and continued to be detected up to 8 weeks, and both the genes were predominantly expressed in the testis. In addition to the testis, the $r g C l-2 B$ gene was also expressed in the brain.

\section{Immunoblot analyses}

To examine rgcl-2 protein, an antibody against rgcl-2 was raised in rabbits. Since there is a high similarity of the amino acid sequence between $\mathrm{rgcl}-2 \mathrm{~A}$ and $\mathrm{rgcl}-2 \mathrm{~B}$, we produced the antibody recognizing the amino acid sequence shared by the two proteins (Fig. 1). Specificity of the affinity-purified anti-rgcl-2 antibody was first examined on the blot to which several glutathione $S$-transferase (GST)-fused recombinant proteins were transferred. As shown in Fig. 3A, the anti-rgcl-2 antibody specifically recognized GST-rgcl-2 protein without cross-reactivity to other GST-fusion proteins, indicating that the antibody is specific for rgcl-2. This anti-rgcl-2 antibody was used throughout this study.

We performed immunoblot analyses to examine whether rgcl-2 is expressed in spermatozoa as well as in seminiferous tubules (ST). The proteins for electrophoresis were extracted from rat ST and spermatozoa by a SDS-PAGE sample buffer, separated on electrophoresis, and the separated proteins were transferred to nitrocellulose membranes. On the blots, the anti-rgcl-2 


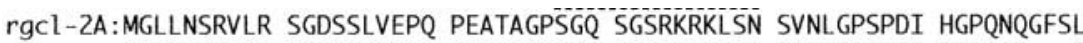
******************************************************** * rgcl-2B:MGLLNSRVLR SGDSSLVEPQ PEATAGPSGQ SGSRKRKLSN SVNLGPSPDI HGPQNQRINL

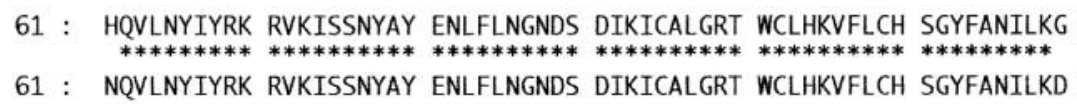

antibody recognized a protein migrating at $\sim 58-60 \mathrm{kDa}$ in the samples of ST, while it detected a 55-57 kDa band in spermatozoa (Fig. 3B). The reason for the difference in the apparent molecular size between them is unclear at present. In spermatozoa, a minor band migrating at $43 \mathrm{kDa}$, which might represent degraded $\mathrm{rgcl}-2$, was also detected by the antibody.

\section{Localization of rgcl-2 in rat testis}

Using the anti-rgcl-2 antibody, we examined the localization of rgcl-2 in frozen sections of adult rat testis by confocal laser scanning microscopy. As shown in Fig. 4A and $\mathrm{C}, \mathrm{rgcl}-2$ was detected in elongating spermatids (steps 15-18) located in the luminal compartment of ST. Rgcl-2 immunostaining was virtually undetectable in round spermatids (steps $1-7$ ) as well as in elongating spermatids of steps 8-14. Spermatogonia, spermatocytes, Sertoli cells and interstitial cells were also devoid of immunofluorescence for rgcl-2 (Fig. 4C). Replacement of the anti-rgcl-2 antibody with preimmune serum gave no specific staining (Fig. 4B). At higher

\begin{abstract}
Figure 1 Predicted amino acid sequences of rat rgcl-2A (accession no. XM_228797) and rgcl-2B (accession no. BC083583). A polyclonal antibody was raised against the synthetic peptide (SGQSGSRKRKLSN) corresponding to 28-40 amino acid residues of rgcl-2 (dotted line). Asterisks denote shared identical amino acid residues between the two proteins. $\mathrm{RgCl}-2 \mathrm{~A}$ showed $90.56 \%$ identity with $\mathrm{rgcl}-2 \mathrm{~B}$. Both rgcl-2A and rgcl-2B contain BTB domain at 80-191 amino acid residues.
\end{abstract}

magnification, $\mathrm{rgcl}-2$ immunofluorescence was found to be present in the cytoplasm of elongating spermatids as well as in the flagella-like structures protruding from elongating spermatids (Fig. 4D).

We next performed confocal laser scanning microscopy to examine whether rgcl-2 is present in rat spermatozoa. In spermatozoa purified from epididymis, a marked immunosignal for rgcl-2 was detected in the flagella. The middle piece, whose length is $\sim 69 \mu \mathrm{m}$ in rat spermatozoa, was strongly labeled by the anti-rgcl-2 antibody, while rgcl-2 immunofluorescence in the principal and end pieces was weak or undetectable (Fig. 4E). Although a weak rgcl-2 immunosignal was also observed in the sperm heads, it might be non-specific because of detection of similar immunosignals in the control samples labeled with the preimmune serum (Fig. 4F).

\section{Immunoelectron microscopy}

To determine the precise localization of $\mathrm{rgcl}-2$ in sperm flagella, sonicated rat spermatozoa, which were permeable to antibodies, were processed for 
A

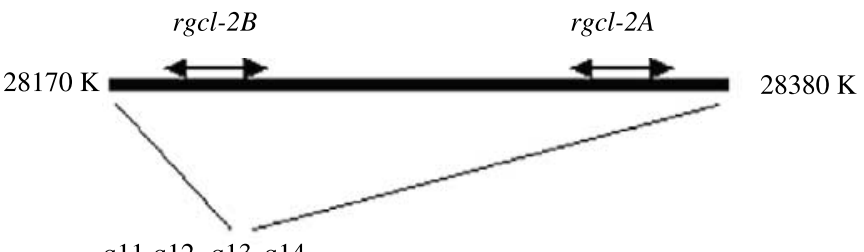
q11 q12 q13 q14

q37

rat $\mathrm{X}$ chromosome

B
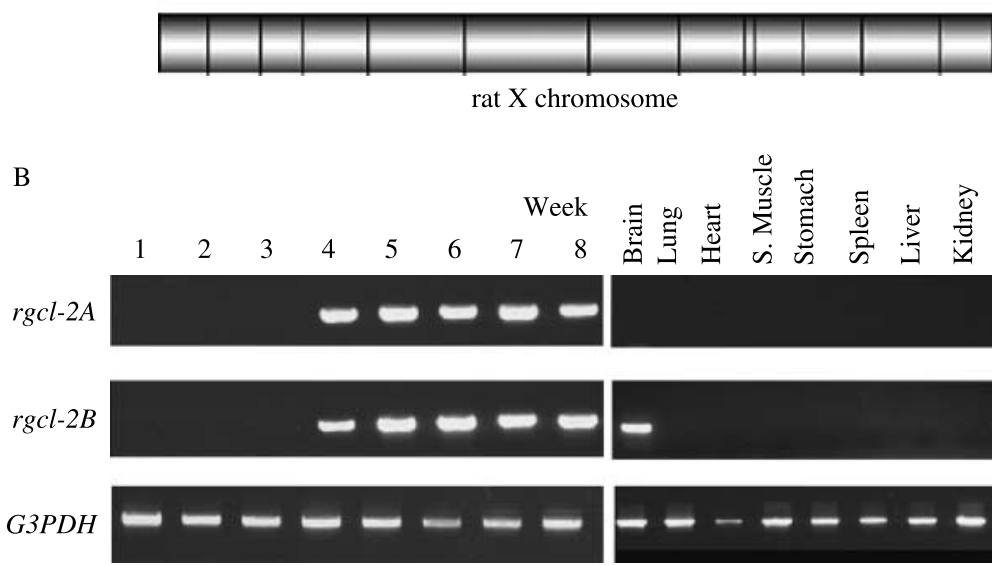

pre-embedding immunoelectron microscopy using the anti-rgcl-2 antibody. The majority of gold particles complexed with the antibody were present on the surface of ODF without immunolabeling of residual mitochondrial sheath and perforatorium (Fig. 5A). In cross-sections of partially disrupted or fractured flagella (Fig. 5B and C), immunogold labeled the abaxial (convex) surface of ODF that faces mitochondrial sheath. Inner (axonemal) side of ODF was devoid of immunolabeling (Fig. 5C). A similar staining pattern of immunogolds was identified in scattered ODF in which immunogolds predominantly labeled the abaxial (convex) surface of ODF with rare labeling on the adaxial (concave) surface (Fig. 5A, inset). Fibrous sheath was never labeled by immunogolds (not shown). Little or no labeling was noticed in the control samples in which the primary antibody was replaced by preimmune serum (Fig. 5D).

\section{Discussion}

The flagellum, which is essential for sperm movement to reach oocytes in the female genital tract, is separated into four regions: the connecting, middle, principal, and end pieces. The core component of flagella is the axoneme, whose prominent components are the central pair of microtubules and nine outer doublet-microtubules. Each outer doublet-microtubule is composed of tubule $\mathrm{A}$ and $\mathrm{B}$, which are composed of protofilaments consisting of tubulin heterodimers, dyneins, and other microtubule-associated proteins (Gibbons 1981, Mohri 1993, Nojima et al. 1995, Sullivan 1998). The flagellum of mammalian spermatozoa has two additional cytoskeletal components: fibrous sheath in the principal
Figure 2 (A) Mapping of $\mathrm{rgCl}-2$ genes on rat $\mathrm{X}$ chromosome. Two intron-less rgcl-2 genes, designated as $\mathrm{rgCl}-2 \mathrm{~A}$ and $\mathrm{rgCl}-2 B$, are mapped on two loci of Xq13, spanning $\sim 150 \mathrm{~kb}$. (B) Expression analysis of $r g C l-2$ genes. RT-PCR analysis was carried out to examine the expression levels of $\mathrm{rgCl}-2 \mathrm{~A}$ and $\mathrm{rgCl}-2 B$ in testes of 1 - to 8 -week-old rats. PCR products of both the genes were first detected at 4 weeks postnatal development and continued to be detected up to 8 weeks (left panels). RT-PCR analysis showed that the $r g C l-2 A$ gene was highly expressed in the testis without amplification in other organs examined, while the $\mathrm{rgCl}-2 B$ gene was found to be expressed in the brain as well as in the testis. The expression of G3PDH is displayed as a control for PCR amplification. piece and ODF in the middle and principal pieces of the sperm tail. ODF consists of nine fibers, which encompass the axoneme. At its anterior end, ODF make a close contact with the connecting piece and extend posteriorly for varying lengths into the principal piece. ODF, which differ from one another in terms of their size and cross-sectional profile at the ultrastructural level, are not uniform structures. They are composed of a thin, striated cortical layer (cortex) and an electrondense inner medulla (Fawcett 1975). The cortex is continuous to satellite fibrils located at the adaxial surface of ODF.

The Drosophila germ cell-less $(g c l)$ gene product, which is a component of the germ plasma, is required for primordial germ cell formation (Jongens et al. 1992, 1994, Robertson et al. 1999). A mouse homolog of gcl, mgcl-1, is expressed ubiquitously, with the highest levels of expression occurring in the course of spermatogenesis and localized to the nuclear envelope (Kimura et al. 1999, Leatherman et al. 2000). Defects of mgcl-1 in mice impaired fertility and produced abnormal sperm morphology, such as insufficient chromatin condensation, abnormal acrosome structures, and defects of the sperm tail (Kimura et al. 2003). In this study, we investigated the expression profiles of ten genes chosen from a database. Among them, we directed our attention to one gene, rat $\mathrm{gCl}-2(\mathrm{rgCl}-2)$, which is predominantly expressed in the testis and its expression level was up-regulated during testis development. Rgcl-2 protein contains BTB/POZ domain, which is also retained in both Drosophila gcl and mgcl-1. Mouse mgcl-1 protein (AF163665) has $47.3 \%$ identity with mouse mgcl-2 (NM_027955), and rat rgcl-1 (AY862307) has 47.1\% identity with rat rgCl-2A (XM_228797). Thus, BTB/POZ 
A

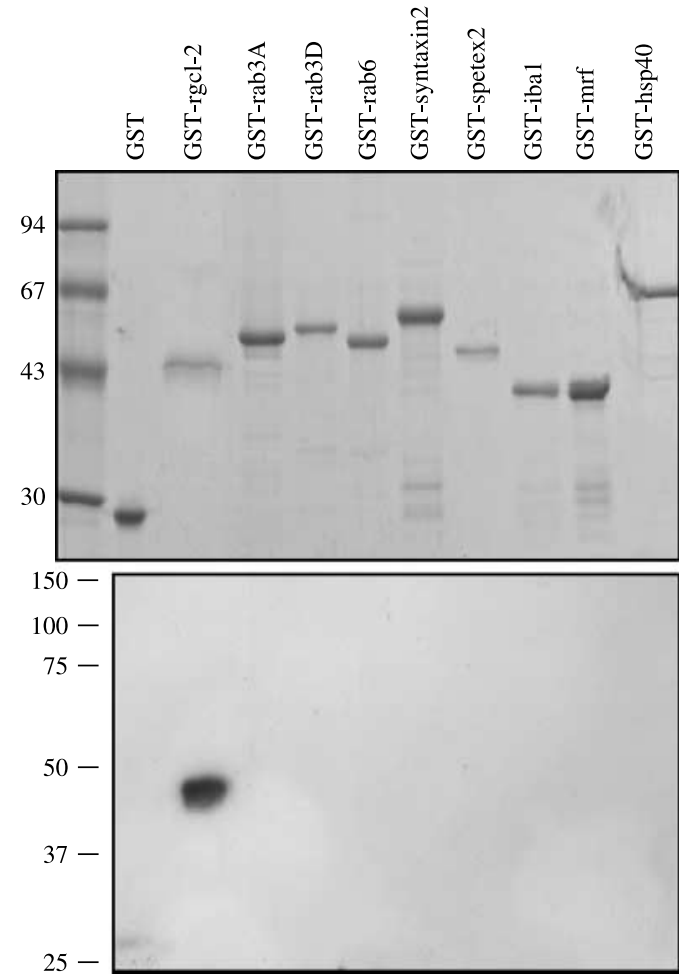

B

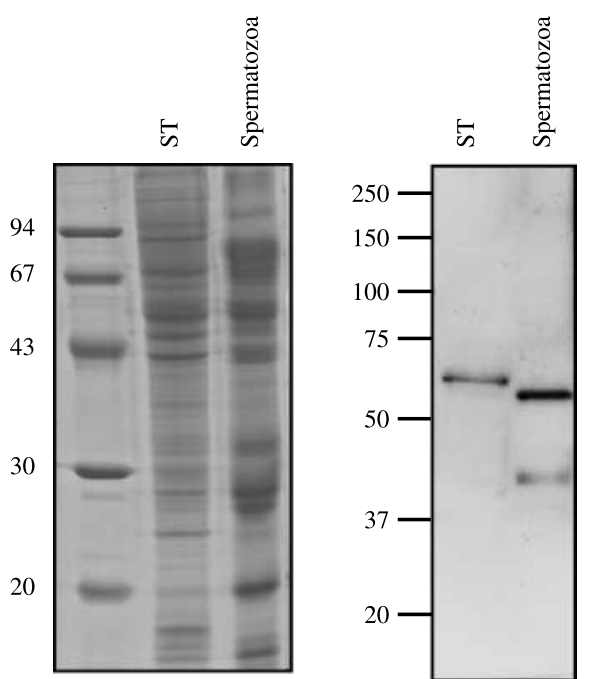

Figure 3 Immunoblot analysis of rgcl-2. (A) Specificity of the antibody against rgcl-2. Recombinant rgcl-2, rab3A, rab3D, rab6, syntaxin2, spetex2, iba1, mrf, and hsp40 were produced in E. coli as GST-fusion proteins and separated by SDS-PAGE. Proteins were either stained with Coomassie Brilliant Blue (upper panel) or transferred to a nitrocellulose membrane for immunoblot analysis using the antibody against rgcl-2 (lower panel). The antibody specifically reacts with a 47 kDa GST-rgcl-2 protein. Molecular mass standards are shown on the left in kDa.

(B) Proteins extracted from the seminiferous tubules (ST) of adult testis and purified spermatozoa were separated by SDS-PAGE and either stained with Coomassie Brilliant Blue (left panel) or subjected to immunoblot analysis using the anti-rgcl-2 antibody (right panel). A band migrating at $\sim 58-60 \mathrm{kDa}$ was detected in ST. A rgcl-2-positive band in spermatozoa migrated at 55-57 kDa. Molecular masses of the standard proteins are shown in the left in kDa. domain is found in both gcl-1 and gcl-2, but identity of the amino acid sequence between them is relatively low.

Rat $\mathrm{rgCl}^{-1}$ gene is present at $4 \mathrm{q} 34$ of chromosome 4 as a single copy gene, whereas rat genome contains duplicate $\mathrm{rgCl}_{-2}$ genes, $\mathrm{rgCl}_{-} \mathrm{AA}$ and $\mathrm{rgCl}-2 \mathrm{~B}$, both of which are located at q13 of the $X$ chromosome. RT-PCR analysis showed that the two genes exhibited similar expression patterns. These intron-less paralog genes are probably produced by gene duplication during evolution. In addition, $\mathrm{rgcl}-2 \mathrm{~A}$ and $\mathrm{rgcl}-2 \mathrm{~B}$ showed $94.39 \%$ identity at the nucleic acid level and $90.56 \%$ identity at the amino acid level. The similarity of these two molecules makes it difficult to distinguish them using the antibody produced in this study.

Rgcl-2 protein was not only detected in the cytoplasm of elongating spermatids of steps 15-18 in rat testis but also retained in spermatozoa as a flagellar component after spermiation. Confocal laser scanning microscopy clearly revealed that $\mathrm{rgcl}-2$ is predominantly localized in the middle piece of flagella of rat spermatozoa without distinct expression in the principal and end pieces. These data suggest that rgcl-2 is synthesized in the cytoplasm of elongating spermatids, and at least a part of it is integrated into the middle piece of spermatozoa during spermiogenesis. To further elucidate the molecular localization of rgcl-2 in mature spermatozoa, we performed pre-embedding immunogold electron microscopy by which we discovered that $\mathrm{rgcl}-2$ is present at the cortex of ODF and not on the adaxial (concave) surface of ODF. Therefore, we concluded that rgcl-2 is a new component of ODF in sperm flagella. However, we could not exclude the possibility that rgcl-2 is also present at the medulla of ODF since the anti-rgcl-2 antibody is not able to penetrate into ODF in the samples prepared for pre-embedding immunoelectron microscopy.

Although the physiological function of ODF remains to be determined, several hypotheses have been proposed. It has been noted that ODF are either lacking or incompletely developed in non-mammalian species and that the appearance of ODF during evolution seems to coincide with the development of internal fertilization. Therefore, it can be speculated that ODF have evolved to overcome a greater resistance to sperm locomotion in the female reproductive tract and act as structural reinforcements that enhance the tensile strength of sperm flagella (Fawcett \& Ito 1965, Baltz et al. 1990). Another possibility is that ODF work as force multipliers to increase the tensile strength of the sperm tail as well as improve the bending torque of the tail (Lindemann 1996).

There is a narrow space between ODF and mitochondrial sheath in which an electron-dense matrix, called the submitochondrial reticulum (SMR), exists (Olson \& Winfrey 1990). The SMR is attached to the overlaying outer mitochondrial membrane and extends from the connecting piece to the annulus in 

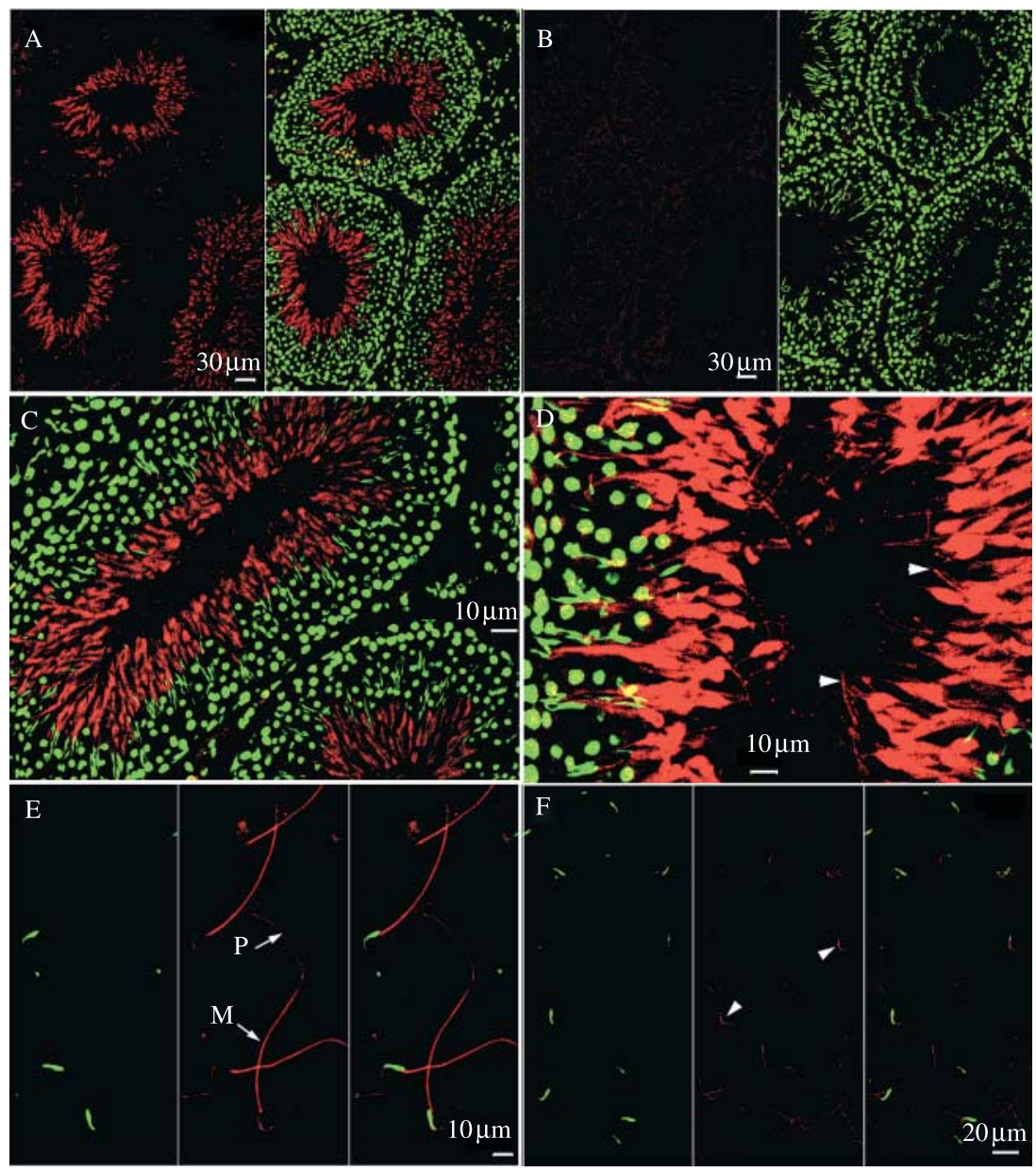

Figure 4 Immunohistochemical localization of rgcl-2 in the seminiferous tubules of adult rat testis and purified spermatozoa. Frozen sections of rat testis and purified spermatozoa were stained with the anti-rgcl-2 antibody followed by incubation with Cy3-conjugated goat anti-rabbit IgG (red color). Immunostained samples were counterstained by SYTOX Green to visualize nuclear DNA (green color). In A and B, confocal images produced by superposition of rgcl-2 (left) and SYTOX green are shown in the right panels. In $\mathrm{C}$ and $\mathrm{D}$, only merged images are shown. In $\mathrm{E}$ and F, superposition of SYTOX green (left) and rgcl-2 (center) was shown in the right panels. In the testis sections (A), rgcl-2 immunosignal was observed in spermatogenic cells located at the luminal compartment of the tubules. Replacement of the anti-rgcl-2 antibody with preimmune serum produced no specific immunostaining (B). At high magnification, the cytoplasm of elongating spermatids was found to be immunostained by the antibody (C). Flagella protruded from elongating spermatids were also positive for rgcl-2 (D, arrowheads). In purified spermatozoa (E), rgcl-2 immunosignal was found to be present in the middle piece of spermatozoa ( $M$, the length of the rat middle piece is $\sim 69 \mu \mathrm{m}$ ), but scarcely detected in the principal piece $(P)$. Replacement of the antibody with the preimmune serum produced no specific immunostaining of the flagella except a weak signal seen in the head region of spermatozoa ( $\mathrm{F}$, arrowheads). spermatozoa. In addition, we have recently reported that Tektin4 and Tektin5, new members of the TEKTIN family, are associated with the cortex of ODF and the inner surface of mitochondria sheath respectively (Iida et al. 2006b, Murayama et al. 2007). It is therefore probable that Tektin4, Tektin5, and rgcl-2 interact either with each other or with some molecules in SMR to tether the axoneme-ODF complex to the mitochondrial sheath by which physiological connection between flagellar components is maintained. Further studies of these molecules should provide additional information and understanding for the molecular architecture and complexity of sperm flagella.

\section{Materials and Methods}

\section{RNA isolation, CDNA synthesis, and RT-PCR}

Investigations were conducted in accordance with the National Research Council publication, Guide for Care and Use of Laboratory Animals. Total RNAs were isolated by QuickPrep Total RNA Extraction Kit (GE Healthcare BioScience Corp., Piscataway, NJ, USA) from testis, lung, kidney, intestine, stomach, brain, heart, liver, skeletal muscle, and spleen of 12-week-old Wistar male rats. Total RNA was also isolated from the testis of 1 - to 8-week-old rats. cDNA strands were synthesized from $3 \mu \mathrm{g}$ total RNA by using a First-Strand cDNA Synthesis Kit (Toyobo, Osaka, Japan) with oligo dT primer. The reverse-transcribed cDNA was used as a PCR template to synthesize a gene. PCR was performed using LA Taq DNA polymerase (Takara, Tokyo, Japan). Primers for glyceraldehyde3-phosphate dehydrogenase were $5^{\prime}$-TGA AGG TCG GTG TCA ACG GAT TTG GC-3' (forward) and 5'-CAT GTA GGC CAT GAG GTC CAC CAC-3' (reverse). The primers used to amplify the full-length of rat gCl-2 ( $\mathrm{rgCl}-2 \mathrm{~A})$ were $5^{\prime}$-ATG GGG CTT TTA AAC AGC AGG GTC-3' (forward) and 5'-ACT ACT TGT TTT CAG CAT TTC CTA GG-3' (reverse). The PCR-amplified DNA was cloned into pGEM-T Easy Vector (Promega Corp.) and sequenced using a DNA sequencer (Applied Biosystems, Foster City, CA, USA). To amplify $\mathrm{rgcl}-2 \mathrm{~A}$ and $\mathrm{rgcl}-2 \mathrm{~B}$ separately, RT-PCR was performed using $5^{\prime}$-GTG CCC TGG GAA GAA CAT GGT G-3' (forward) that is common to both genes and gene-specific reverse primer; 5'- GAG GAA CCA TCG CAC TCC TGA TG $-3^{\prime}$ for $r g C l-2 A$ and $5^{\prime}-$ ATT GAT CGT TTG TGG TCC AAT TGC C $-3^{\prime}$ for rgCl-2B.

\section{Antibody production}

The peptide used for raising the antibody is derived from $\mathrm{N}$-terminal hydrophilic region of rgcl-2 (SGQSGSRKRKLSN; 

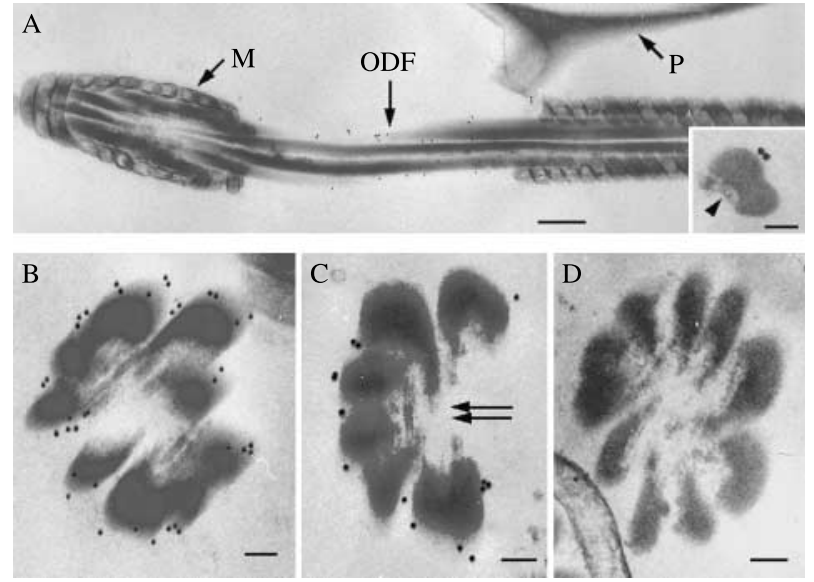

Figure 5 Pre-embedding immunoelectron microscopy of $\mathrm{rgcl}-2$ in rat spermatozoa. Sonicated spermatozoa were fixed and processed for immunogold labeling using the anti-rgcl-2 antibody and $10 \mathrm{~nm}$ immunogolds. In longitudinal sections of outer dense fibers (ODF) in the middle piece $(5 \mathrm{~A})$, the majority of immunogolds complexed with the antibody is associated with the surface of ODF, not detected on mitochondrial sheath $(M)$ and perforatorium $(P)$. In cross-sections of partially disrupted flagella of the middle piece, $10 \mathrm{~nm}$ golds are observed at the abaxial surface of ODF (B) without labeling on the concave surface of ODF (double arrows in $\mathrm{C}$ ). Immunogolds are also detected at the cortex of scattered ODF (A, inset) without labeling satellite fibrils (an arrowhead). Little or no labeling is seen in the control samples in which the primary antibody is replaced by preimmune serum (D). Bars: (A) $300 \mathrm{~m}$ and (B-D, and inset of A) $100 \mathrm{~nm}$.

Fig. 1). The peptide was coupled to keyhole limpet hemocyanin (KLH, Pierce, Rockford, IL, USA). The peptide coupled to KLH (1 $\mathrm{mg}$ total dose) was dissolved in $1 \mathrm{ml}$ saline, emulsified with $1 \mathrm{ml}$ Freund's complete adjuvant, and injected at multiple sites on the back of a rabbit as described previously (Katafuchi et al. 2000, Doiguchi et al. 2002a). The antiserum was collected within 2 weeks after the third injection. Affinity purification of the antibody was carried out over a matrix of the peptide coupled to Formyl-Cellulofine (Seikagaku Kougyo, Nagoya, Japan), as described previously (Matsuyama et al. 2005, lida et al. 2006a).

\section{Preparation of GST-fusion proteins}

Rat rgCl-2 gene has an ORF of 1497 nucleotides encoding 498 amino acid residues. A 183 amino acid residue length (17-199 amino acids) of rgcl-2A was PCR-amplified and cloned in frame to the $\mathrm{COOH}$ terminus of GST using pGEX-4T-1 system (GE Healthcare BioScience Corp). Recombinant protein was expressed in Escherichia coli and purified onto glutathioneSepharose (GE Healthcare BioScience Corp.), as described previously (Iwamoto et al. 2005). The molecular size of GSTrgcl-2A is $\sim 47 \mathrm{kDa}$. The GST-fused recombinant proteins, rab3A, rab3D, rab6 (lida et al. 1999), syntaxin 2 (Katafuchi et al. 2000), spetex-2 (Iwamoto et al. 2005), iba1, mrf (lida et al. 2001), and hsp40 (Doiguchi et al. 2007), were similarly produced and purified. These recombinant proteins were used for immunoblot analysis.

\section{Immunoblot analysis}

Testes of ether-anesthetized adult Wistar rats were immersed in PBS on ice, and the capsule (tunica albuginea) was torn away by tweezers. ST released from testes were untangled and washed several times in PBS at $4{ }^{\circ} \mathrm{C}$ with gentle agitation to remove interstitial cells. Spermatozoa, which were collected from the epididymis of adult rats, were purified by a Percoll density gradient centrifugation as reported previously (Katafuchi et al. 2000, Doiguchi et al. 2002b). Both ST and purified spermatozoa were solubilized directly in a SDS-PAGE sample buffer followed by centrifugation at $16000 \mathrm{~g}$ (15 000 r.p.m.) for $20 \mathrm{~min}$. Clarified supernatants were used as samples for SDS-PAGE and immunoblot analysis. The sample proteins of spermatozoa and ST prepared for SDSPAGE were separated on $12 \%$ acrylamide gel, and separated proteins were either stained with Coomassie Brilliant Blue or transferred to nitrocellulose sheets. The sheets were incubated for $3 \mathrm{~h}$ with the affinity-purified anti-rgcl-2 antibody diluted 1:10 000 with a blocking buffer (PBS containing 5\% nonfat milk and $0.05 \%$ Tween-20), followed by incubation with HRPconjugated goat anti-rabbit IgG (Bio-Rad) diluted 1:3000 in the same buffer. Antigen-antibody complexes were visualized using an ECL-Plus detection kit (GE Healthcare Bioscience Corp). GST-fused proteins were similarly processed for immunoblot analysis.

\section{Immunocytochemistry}

Adult rat testes were fixed in $4 \%$ paraformaldehyde in PBS at $4{ }^{\circ} \mathrm{C}$ for $4 \mathrm{~h}$, washed three times in PBS, incubated in PBS containing $50 \mathrm{mmol} / \mathrm{l} \mathrm{NH}_{4} \mathrm{Cl}$ for $30 \mathrm{~min}$, and then rinsed in PBS. After infiltration of $20 \%(\mathrm{w} / \mathrm{v})$ sucrose in PBS, the testes were immersed in OCT compound (Tissue-Tek, Miles Inc., Elkhart, IN, USA) and immediately frozen by liquid nitrogen. The frozen sections of $8 \mu \mathrm{m}$ thickness were cut by a cryostat (CM1850; Leica, Nussloch, Germany). The sections were washed in PBS, exposed to $0.1 \%$ Triton X-100 in PBS, and then incubated with the anti-rgcl-2 antibody diluted 1:400 with the blocking buffer followed by incubation with goat anti-rabbit IgG conjugated with Cy3 (GE Healthcare BioScience Corp). For DNA staining, immunostained samples were incubated for 30 min with PBS containing SYTOX Green (1:10 000 dilution, Molecular Probes, Eugene, OR, USA). The samples were then washed with PBS and examined by a confocal laser scanning microscope (Olympus LSM-GB 200, Tokyo, Japan). Purified spermatozoa were fixed, washed in PBS, attached to poly-Llysine coated glass slides, and then processed for immunohistochemistry, as described above. For controls, the primary antibody was replaced by preimmune serum.

\section{Pre-embedding immunoelectron microscopy}

Samples for immunoelectron microscopy were prepared by the method described previously (lida et al. 2006b). In brief, purified rat spermatozoa were exposed at $4{ }^{\circ} \mathrm{C}$ for $60 \mathrm{~min}$ to $50 \mathrm{mmol} / \mathrm{l}$ sodium borate buffer $(\mathrm{pH} 8.0)$ containing $1 \%$ Triton $\mathrm{X}-100$ to remove the plasma membrane. The mitochondrial sheath was partially disrupted by this treatment. After 
extraction, the samples were centrifuged at $1000 \mathrm{~g}$ and the pellet was washed two times with $50 \mathrm{mmol} / \mathrm{l}$ Tris- $\mathrm{HCl}(\mathrm{pH} \mathrm{8.0})$. The samples in $50 \mathrm{mmol} / \mathrm{l}$ Tris- $\mathrm{HCl}(\mathrm{pH}$ 8.0) were probesonicated at maximum power for four 10-s bursts, and centrifuged at $5000 \mathrm{~g}$ for $10 \mathrm{~min}$ to make pellets. The pellets were fixed in PBS containing $4 \%$ paraformaldehyde and $0.2 \%$ glutaraldehyde at $4{ }^{\circ} \mathrm{C}$ for $2 \mathrm{~h}$, washed in PBS, and incubated for $30 \mathrm{~min}$ in PBS containing $0.2 \%$ gelatin and $0.2 \%$ BSA. The samples were immunostained overnight with the anti-rgcl-2 antibody, followed by incubation for $3 \mathrm{~h}$ with $10 \mathrm{~nm}$ goldconjugated goat anti-rabbit IgG (GE Healthcare BioScience Corp). For controls, the primary antibody was replaced by preimmune serum. After immunostaining, the samples were washed in PBS and fixed in 3\% glutaraldehyde in $0.1 \mathrm{~mol} / \mathrm{l}$ cacodylate buffer ( $\mathrm{pH} 7.4$ ), postfixed in $1 \%$ osmium tetroxide, dehydrated in a graded series of ethanols, and embedded in epoxy resin as reported previously (Katafuchi et al. 2000). Ultrathin sections were examined in a Hitachi $\mathrm{H}-600$ electron microscope after staining with uranyl acetate and lead citrate.

\section{Acknowledgements}

This work was supported by a Grant-in-Aid for Scientific Research from the Japan Society for the Promotion of Science. The authors declare that there is no conflict of interest that would prejudice the impartiality of this scientific work.

\section{References}

Baltz JM, Williams PO \& Cone RA 1990 Dense fibers protect mammalian sperm against damage. Biology of Reproduction 43 485-491.

Clermont Y 1972 Kinetics of spermatogenesis in mammals: seminiferous epithelium cycle and spermatogonial renewal. Physiological Reviews 52 198-236.

Doiguchi M, Yamashita H, Ichinose J, Mori T, Shibata Y \& lida H 2002a Complementary DNA cloning and characterization of rat spergen-1, a spermatogenic cell-specific gene-1, containing a mitochondria-targeting signal. Biology of Reproduction 66 1462-1470.

Doiguchi M, Mori T, Toshimori K, Shibata Y \& lida H 2002b Spergen-1 might be an adhesive molecule associated with mitochondria in the middle piece of spermatozoa. Developmental Biology 252 127-137.

Doiguchi M, Kaneko T, Urasoko A, Nishitani H \& lida H 2007 Identification of heat shock protein Hsp40/DnaJ-1 as an acrosome- and a tailassociated component in rodent spermatozoa. Molecular Reproduction and Development 74 223-232.

Eddy EM 2002 Male germ cell gene expression. Recent Progress in Hormone Research 57 103-128.

Fawcett DW 1975 The mammalian spermatozoon. Developmental Biology 44 394-436.

Fawcett DW \& Ito S 1965 The fine structure of bat spermatozoa. American Journal of Anatomy 116 567-610.

Gibbons IR 1981 Cilia and flagella of eukaryotes. Journal of Cell Biology 91 107-124.

Hong S, Choi I, Woo JM, Oh J, Kim T, Choi E, Kim TW, Jung YK, Kim DH, Sun CH, Yi GS, Eddy EM \& Cho C 2005 Identification and integrative analysis of 28 novel genes specifically expressed and developmentally regulated in murine spermatogenic cells. Journal of Biological Chemistry $2807685-7693$.

lida H, Yoshinaga Y, Tanaka S, Toshimori K \& Mori T 1999 Identification of Rab3A GTPase as an acrosome-associated GTP-binding protein in rat sperm. Developmental Biology 211 144-155.

lida H, Doiguchi M, Yamashita H, Sugimachi S, Ichinose J, Mori T \& Shibata Y 2001 Spermatid-specific expression of Iba1, an ionized calcium-binding adapter molecule-1, in rat testis. Biology of Reproduction 64 1138-1146. lida H, Honda Y, Matsuyama T, Shibata Y \& Inai T 2006a Spetex-1: a new component in the middle piece of flagellum in rodent spermatozoa. Molecular Reproduction and Development 73 342-349.

lida H, Honda Y, Matsuyama T, Shibata Y \& Inai T 2006b Tektin 4 is located on outer dense fibers, not associated with axonemal tubulins of flagella in rodent spermatozoa. Molecular Reproduction and Development $\mathbf{7 3}$ 929-936.

Iwamoto Y, Kaneko T, Ichinose J, Mori T, Shibata Y, Toshimori K \& lida H 2005 Molecular cloning of rat Spetex-2 family genes mapped on chromosome $15 \mathrm{p} 16$, encoding a $23 \mathrm{kDa}$ protein associated with the plasma membranes of haploid spermatids. Biology of Reproduction 72 284-292.

Jongens TA, Hay B, Jan LY \& Jan YN 1992 The germ cell-less gene product: a posteriorly localized component necessary for germ cell development in Drosophila. Cell 70 569-584.

Jongens TA, Ackerman LD, Swedlow JR, Jan LY \& Jan YN 1994 Germ cellless encodes a cell type-specific nuclear pore-associated protein and functions early in the germ-cell specification pathway of Drosophila. Genes and Development 8 2123-2136.

Katafuchi K, Mori T, Toshimori K \& lida H 2000 Localization of a syntaxin isoform, syntaxin 2, to the acrosomal region of rodent spermatozoa. Molecular Reproduction and Development 57 375-383.

Kimura T, Yomogida K, Iwai N, Kato Y \& Nakano T 1999 Molecular cloning and genomic organization of mouse homologue of Drosophila germ cellless and its expression in germ lineage cells. Biochemical and Biophysical Research Communications 262 223-230.

Kimura T, Ito C, Watanabe S, Takahashi T, Ikawa M, Yomogida K, Fujita $Y$, Ikeuchi M, Asada N, Matsumiya K, Okuyama A, Okabe M, Toshimori K \& Nakano T 2003 Mouse germ cell-less as an essential component for nuclear integrity. Molecular and Cellular Biology 23 1304-1315.

Leatherman JL, Kaestner KH \& Jongens TA 2000 Identification of a mouse germ cell-less homologue with conserved activity in Drosophila. Mechanisms of Development 92 145-153.

Leblond CP \& Clermont Y 1952 Spermatogenesis of rat, mouse, hamster and guinea pig as revealed by the periodic acid-fuchsin sulfurous acid technique. American Journal of Anatomy 90 167-215.

Lindemann CB 1996 Functional significance of the outer dense fibers of mammalian sperm examined by computer simulations with the geometric clutch model. Cell Motility and the Cytoskeleton 34 258-270.

Matsuyama T, Honda Y, Doiguchi M \& lida H 2005 Molecular cloning of a new member of TEKTIN family, tektin4, located to the flagella of rat spermatozoa. Molecular Reproduction and Development 72 120-128.

Mohri H 1993 Role of tubulin and dynein in spermatozoan motility. Molecular Reproduction and Development 36 221-222.

Murayama E, Yamamoto E, Kaneko T, Shibata Y, Inai T \& lida H 2007 Tektin5, a new TEKTIN family member, is a component of the middle piece of flagella in rat spermatozoa. Molecular Reproduction and Development [in press].

Nojima D, Linck RW \& Egelman EH 1995 At least one of the protofilaments in flagellar microtubules is not composed of tubulin. Current Biology 5 158-167.

Olson GE \& Winfrey VP 1990 Mitochondria-cytoskeleton interactions in the sperm midpiece. Journal of Structural Biology 103 13-22.

Robertson SE, Dockendorff TC, Leatherman JL, Faulkner DL \& Jongens TA 1999 Germ cell-less is required only during the establishment of the germ cell lineage of Drosophila and has activities which are dependent and independent of its localization to the nuclear envelope. Developmental Biology 215 288-297.

Shima JE, McLean DJ, McCarrey JR \& Griswold MD 2004 The murine testicular transcriptome: characterizing gene expression in the testis during the progression of spermatogenesis. Biology of Reproduction $\mathbf{7 1}$ 319-330.

Sullivan KF 1998 Structure and utilization of tubulin isotype. Annual Review of Cell Biology 4 687-716.

Received 22 June 2007

First decision 27 July 2007

Accepted 5 September 2007 